\title{
Characterisation of olive fruit for the milling process by using visible/near infrared spectroscopy
}

\author{
Roberto Beghi, ${ }^{1}$ Valentina Giovenzana, ${ }^{1}$ Raffaele Civelli, ${ }^{1}$ Enrico Cini, ${ }^{2}$ Riccardo Guidetti ${ }^{1}$ \\ ${ }^{1}$ Department of Agricultural and Environmental Sciences - Production, Landscape, Agroenergy, \\ University of Milan; ${ }^{2}$ Department of Economics, Engineering, Science and Technology Agriculture \\ and Forestry, University of Florence, Italy
}

\begin{abstract}
Increasing consumption of olive oil and table olives has recently determined an expansion of olive tree cultivation in the world. This trend is supported by the documented nutritional value of the Mediterranean diet. The aim of this work was to test a portable visible/near infrared (vis/NIR) system $(400-1000 \mathrm{~nm})$ for the analysis of physical-chemical parameters, such as olive soluble solid content (SSC) and texture before the olive oil extraction process. The final goal is to provide the sector with post-harvest methods and sorting systems for a quick evaluation of important properties of olive fruit. In the present study, a total of 109 olives for oil production were analysed. Olive spectra registered with the optical device and values obtained with destructive analysis in the laboratory were analysed. Specific statistical models were elaborated to study correlations between optical and laboratory analysis, and to evaluate predictions of reference parameters obtained through the analysis of the visible-near infrared range. Statistical models were processed using chemometric techniques to extract maximum data information. Principal component analysis (PCA) was performed on vis/NIR spectra to examine sample groupings and identify outliers, while partial least square (PLS) regression algorithm was used to correlate samples spectra and phys-
\end{abstract}

Correspondence: Valentina Giovenzana, Department of Agricultural and Environmental Sciences - Production, Landscape, Agroenergy, University of Milan, via Celoria 2, Milano, 20133 Italy.

Tel. +39.02 .50316874 - Fax: +39.02 .50316845 .

E-mail: valentina.giovenzana@unimi.it

Key words: olives, visible/near infrared spectroscopy, ripening parameters, chemometrics, post-harvest.

Acknowledgements: this study received financial support from the European Social Fund for a Post-doctorate Research Fellowship (Progetto Dote Ricerca).

Received for publication: 18 June 2013.

Accepted for publication: 18 September 2013.

(C) Copyright R. Beghi et al., 2013

Licensee PAGEPress, Italy

Journal of Agricultural Engineering 2013; XLIV:e8

doi:10.4081/jae.2013.e8

This article is distributed under the terms of the Creative Commons Attribution Noncommercial License (by-nc 3.0) which permits any noncommercial use, distribution, and reproduction in any medium, provided the original author(s) and source are credited. ical-chemical properties. Results are encouraging. PCA showed a significant sample grouping among different ranges of SSC and texture. PLS models gave fairly good predictive capabilities in validation for SSC $\left(R^{2}=0.67\right.$ and RMSECV\%=7.5\%) and texture $\left(R^{2}=0.68\right.$ and RMSECV\%=8.2\%).

\section{Introduction}

Growing consumption of olive oil and table olives has recently determined an expansion of olive tree (Olea europaea L.) cultivation in many countries throughout the world.

There is increasing evidence to suggest that monounsaturated fatty acids as a nutrient, olive oil as a food, and the Mediterranean diet as a food pattern are associated with a decreased risk of cardiovascular disease, obesity, metabolic syndrome, type 2 diabetes and hypertension (López-Miranda et al., 2010).

Ripening process control is essential. In fact, during olive oil fruits ripening, biochemical processes occur: sugar content decreases with time, while the oil accumulation increases (Cherubini et al., 2009; Salas et al., 2002). Moreover, olives with a high sugar content may present oils with defects because of sugar fermentation during the production process. Therefore, sugar concentration may be considered an index capable of defining an appropriate level of olive ripening for processing (Cherubini et al., 2009).

Furthermore, degradation occurs during the processing and shelflife of extra virgin olive oil and success on the market may also depend on the product's stability. Degradation may result in variations in the nutritional quality of the product, since antioxidant content decreases and free radical content increases, variations in sensory descriptors may reduce appreciation of the product, since aroma, colour, taste and flavour attributes change and some unpleasant sensory phenomena may occur (Zanoni et al., 2005).

During maturation, fruit weight increases. The flesh texture, related to the dry matter content, is a quality parameter for table olive fruits (Beltra et al., 2004). Yousfi et al. (2006) studied changes in quality and phenolic compounds of virgin olive oils during fruit maturation. They confirmed that firmness allowed better discrimination at the initial maturity stages than the other methods tested (harvest date, amount of chlorophylls and carotenoids in the oil).

Studies consistently support the concept that the level of olive ripening may affect oil quality and this also holds true for the quality of table olives.

Marsilio et al. (2001) carried out an experimental investigation on olive fruit cultivars to assess free sugar and polyphenolic compositions and their changes during ripening and processing. Patumi et al. (2002) established olive and olive oil quality after intensive monocone olive growing in different irrigation regimes. Borzillo et al. (2000) evaluated quality of Ointoria table olives during ripening and process- 
ing by biomolecular components.

Diaz et al. (2004) compared three algorithms to classify table olives in four quality categories using computer vision. Classification of table olives according to their quality was carried out after the fermentation process.

Established methods for olive and oil quality assessment are generally based on either colourimetric or chromatography techniques such as high performance liquid chromatography. However, the difficult preparation of samples for this analysis requires a well-equipped laboratory and results are only available after $8-10 \mathrm{~h}$. A limited number of laboratories and the lack of readily available data mean that oil mills must begin the process of oil production without having the necessary information, thus reducing their chances of diversifying production and obtaining products with the desired characteristics.

Therefore, there is a strong need in the modern oil industry for a simple, rapid, and easy-to-use method for objectively evaluating the level of olive ripening. A tool enabling real-time analysis at the receiving station would allow preliminary decision-making about olives during consignment thanks to the rapid analysis of ripening parameters (i.e. soluble solid content, SSC and texture) simultaneously.

Near infrared (NIR) spectroscopy has been shown to be one of the most efficient and advanced tools to monitor process and control product quality in the food industry. It is widely used for rapid quality control of several products (Guidetti et al., 2012).

During fruit ripening, chlorophyll degradation is responsible for the degreening of the ground colour, which is a well-established ripeness indicator for several species. In completely red-pigmented cultivars of fruits such as apples and peaches this process is not visible, being masked by the anthocyanins in the skin. Optical systems were developed to assess the chlorophyll content in these fruits in a non-destructive manner, to estimate ripeness, and to optimise harvesting and postharvest management (Bodria et al., 2004).

Studies available in the literature discuss quality evaluation of olives and olive oil using optical analysis. Salguero-Chaparro et al. (2013), Kavdir et al. (2009), and Conte et al. (2003) considered the application of NIR analysis to intact olives and olive oil production quality control. In 2004, Mailer studied rapid evaluation of olive oil quality by NIR reflectance spectroscopy. Marquez et al. (2005) used optical NIR sensor for on-line virgin olive oil characterisation. Bendini et al. (2007) presented a preliminary evaluation of the application of Fourier transform infrared spectroscopy to control the geographical origin and quality of virgin olive oils. Bellincontro et al. (2012) studied the application of a portable NIR for on-field prediction of phenolic compounds during the ripening of olives. Mailer (2004) calibrated chemical factors, including free fatty acids (FA), induction time, polyphenol content, and FA profiles, for NIR analysis. The results provided evidence of the ability of NIR analysis to measure most olive oil components rapidly and accurately. Morales-Sillero et al. (2011) studied the feasibility of NIR spectroscopy for non-destructive characterisation of table olives.

The application of vis/NIR technology, in order to monitor ripening and estimate quality parameters, has already been carried out on different fruits. Nicolaï et al. (2007) presented a review regarding nondestructive measurements of fruit and vegetable quality by means of NIR spectroscopy. Furthermore, this acquisition technique was proved to be suitable for a direct use to monitor quality parameters, SSC in particular, and good correlations were obtained (Beghi et al., 2013). Using vis/NIR technique, it was possible to estimate changes in the firmness and SSC of stored Red Delicious apples undergoing no detectable change in skin colour (Bodria et al., 2004).

NIR and vis/NIR instrumentation must always be complemented with chemometric analysis to extract useful information present in the spectra (Guidetti et al., 2012). The most used chemometric techniques are the principal component analysis (PCA) as a qualitative analysis of the data and partial last square (PLS) regression analysis to obtain quantitative prediction of the desired parameters (Cen and He, 2007). Therefore, we studied the capability of a portable and non-destructive optical system (vis/NIR spectrophotometer) in combination with multivariate analysis to investigate two parameters (SSC and texture) for the characterisation of olive fruits entering the processing mill. Chemometric tools were used, such as PCA and PLS regression methods. For both parameters (SSC and texture) dedicated chemometric models were created.

\section{Materials and methods}

\section{Sampling}

The experiment was carried out on 109 healthy olives harvested in November and December 2011 on the Montepaldi experimental farm in Florence (Tuscany, Italy). Olive fruits used in this study were Moraiolo and Frantoio (approx. 50\% of each) cultivated in the Province of Florence; these varieties are typical of the Tuscan hills.

Picked fruits taken at random from the bin were measured. Harvested and classified berries were analysed in the laboratory to determine parameters, indicating stage of ripening. Two spectral measurements were taken on individual berries along their equator region. Subsequent to the spectral acquisition, analyses of texture and of SSC of each olive were carried out. For SSC analysis, fruits were destoned and the flesh (pulp) was crushed and measured using a portable refractometer (Pocket Refractometer PAL-1 by ATAG0, Itabashi-ku, Tokyo, Japan). Hardness was assessed using a portable penetrometer (AGROSTA ${ }^{\circledR} 100$ by Agro-Technologie, Forges les Eaux, France) where a spring is compressed onto the fruit and a tip $\left(25 \mathrm{~mm}^{2}\right)$ is displaced (Barreiro et al., 2004). Hardness is expressed as AGR0STA ${ }^{\circledR} 100$ units (0-100).

Two distinct classifications were performed on SSC and texture (Table 1). In both cases, three arbitrary classes $(a, b$, and $c$ ) were created to identify different ranges for each parameter. Class definition was based on a window for the central class $b$ equal to mean value $\pm 3 *$ standard error.

Spectral data and destructive reference analysis were used to elaborate chemometric predictive models.

\section{Visible/near infrared system device}

Spectral acquisitions were realised on samples using an optical portable system (JAZ vis/NIR spectrophotometer, OceanOptics, Inc., Dunedin, FL, USA) operating in the $400-1000 \mathrm{~nm}$ wavelength range. The JAZ equipment is composed of five components: i) vis/NIR lighting system; ii) fibre optic probe for reflection measurement; iii) spectrophotometer; iv) hardware for data acquisition and instrument control; v) power battery.

Table 1. Arbitrary classes based on different ranges of soluble solid content and texture.

\begin{tabular}{|c|c|c|c|}
\hline \multicolumn{2}{|c|}{ SSC } & \multicolumn{2}{|c|}{ Texture } \\
\hline Class & ${ }^{\circ}$ Brix & Class & Hardness units \\
\hline $\mathrm{a}$ & $<17$ & $\mathrm{a}$ & $>80$ \\
\hline b & $17.1-19.9$ & b & $70.1-79.9$ \\
\hline c & $>20$ & c & $<70$ \\
\hline
\end{tabular}


Spectra were acquired in reflectance: light radiation was guided to the sample through a Y-shaped, bidirectional fibre optic probe (Ocean0ptics, USA). Y-shaped fibre allowed light from a halogen lamp to be guided to illuminate the sample while simultaneously collecting the radiation coming from the berry and guiding it back to the spectrophotometer. The tip of the optical probe was equipped with a soft plastic cap to ensure contact with sample skin during measurements, while minimising environmental light interference.

The integrated spectrophotometer was equipped with a diffractive grating for spectral measurements, optimised in the range 400-1000 $\mathrm{nm}$, and a CCD sensor with a 2048 pixel matrix, corresponding to a nominal resolution of $0.3 \mathrm{~nm}$.

\section{Data processing}

Chemometric analysis was performed using The Unscrambler software package (version 9.6, CAMO ASA, Oslo, Norway). Different pretreatments were applied to the vis/NIR spectra in order to maximise the accuracy of the model. Moving-averaged smoothed spectra, multiplicative scatter correction and derivatives were calculated before building the calibration models. The first and second derivatives were performed using Savitzky-Golay transformation and smoothing (15 point and second order filtering).

A qualitative analysis was carried out using a PCA tool to find possible clustering of the olive spectra (Massart et al., 1997; Naes et al., 2002). PCA was performed according to SSC and texture ranges to better highlight differences in spectra. Moreover, a quantitative analysis was performed using all samples available for the creation of a chemometric regression model for each parameter considered. The vis/NIR spectra were correlated with the ripeness parameters (SSC and texture) using the PLS regression algorithm. By this method, an orthogonal basis of latent variables is constructed one by one in such a way that they are oriented along directions of maximal covariance between spectral matrix X and response vector Y. This method ensures that the latent variables are ordered according to their relevance for predicting the $\mathrm{Y}$ variable. Interpretation of the relationship between the $\mathrm{X}$ data and the $Y$ data (the regression model) is then simplified, as this relationship is concentrated on the smallest possible number of latent variables. The PLS method performs particularly well when the various $\mathrm{X}$ variables express common information, i.e. when there is a large amount of correlation, or even colinearity, which is the case for spectral data of intact biological material (Nicolaï et al., 2007).

To evaluate model accuracy, the statistics used were the coefficient of determination in calibration $\left(\mathrm{R}^{2}\right.$ cal $)$, coefficient of determination in cross-validation $\left(\mathrm{R}^{2}{ }_{\mathrm{cv}}\right)$, root mean square error of calibration (RMSEC), and root mean square error of cross-validation (RMSECV). Cross-validation is an internal validation method, usually used in the case of a small number of samples available for regression. With cross-validation, some samples are kept out of the calibration and used for prediction. This is repeated until all samples have been kept out once. In this case, full cross-validation was used, so only one sample at a time is kept out of the calibration.

Coefficient of determination $\left(\mathrm{R}_{\text {cal }}\right.$ and $\left.\mathrm{R}_{\mathrm{cv}}^{2}\right)$ :

$$
\mathrm{R}_{\mathrm{cal}}^{2} \text { or } \mathrm{R}_{\mathrm{cv}}^{2}=1-\frac{\sum_{i=1}^{n}\left(y_{i}-\hat{y}_{i}\right)^{2}}{\sum_{i=1}^{n}\left(y_{i}-\bar{y}\right)^{2}}
$$

where: $\mathrm{y}_{\mathrm{i}}$ are the reference values, $\hat{y}_{i}$ are the values predicted by the PLS model, and $\bar{y}$ is the averaged reference value.

RMSEC AND RMSECV $=\sqrt{\frac{\sum_{i=1}^{n}\left(Y i-Y^{\prime}\right)^{2}}{n}}$

where:

$n$ is the number of validated objects, and $y_{i}^{\prime}$ and $y_{i}$ are the predicted and measured values of the $i^{\text {th }}$ observation in the calibration or validation set, respectively. This value gives the average uncertainty that can be expected for predictions of future samples.

The best calibrations were selected by minimising the RMSECV. Percentage errors of cross-validation (RMSECV\%) were also calculated as:

RMSECV (\%) = RMSECV / averaged reference values of each parameter.

\section{Results and discussion}

\section{Qualitative analysis}

Figures 1 and 2 show average spectra of the three analysed classes of SSC and texture, respectively. A very different trend could be noticed among classes both in the area of the visible region $(400-700 \mathrm{~nm})$ and in the NIR region (700-900 $\mathrm{nm}$ ) for each reference parameter considered. The main peak is detectable at $680 \mathrm{~nm}$, corresponding to the absorption peak of chlorophyll.

A correlation between reflectance in the visible band and the reference parameters considered can be observed.

As expected, the average spectrum demonstrates significant differences among the three classes, with dramatic changes in the visible spectral range, from green berries $(a)$ to the completely black-pigmented olives $(c)$, especially linked to anthocyanin accumulation. This leads to a decrease in reflectance in the visible band associated with the anthocyanin absorption peak centred around $540 \mathrm{~nm}$. Accordingly, the green samples, with anthocyanin content near to zero, reflect more light than pigmented olives.

Firmness decreases in parallel with a decrease in reflectance absorption in the visible range, until reaching a minimum and then remain-

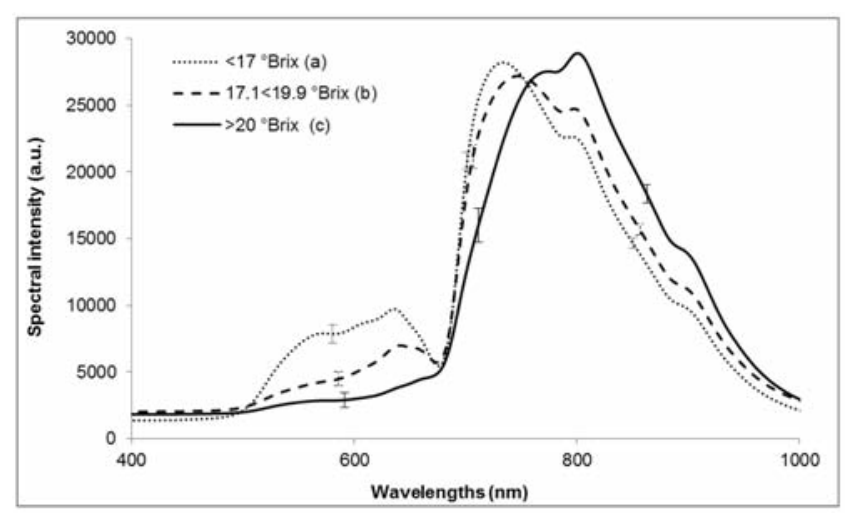

Figure 1. Average raw spectra of 109 olives grouped in three classes of soluble solid content. Bars indicate the standard error within each group at different wavelengths $(a<17 ; 17.1<b<19.9 ; c>20)$. 
ing constant.

PCA was carried out on spectra, and grouped according to SSC and texture ranges.

Ninety-nine percent of the total data variance is explained by the first three principal components (PCs). In particular, PC1 explained $93 \%$ of the variability, PC2 5\% and 1\% is explained by PC3. The combination plan between PC1 and PC2 is shown in Figures 3 (SSC grouping) and 4 (texture grouping).

Concerning SSC, a fairly good sample separation in the PCs plan was obtained. PC1 allows a good separation between olives belonging to classes $a$ and $c$. The PCs plan highlights the presence of a few outliers belonging to class $a$ that are placed in class $c$. Less obvious is the association of samples $b$ to a distinct group. In fact, samples belonging to class $b$ are divided into nearly equal parts along the PC1. The $42 \%$ of samples of class $b$ has negative values of PC1 while $58 \%$ of them have positive values. The PCA highlighted an increase in SSC in olives from high positive values to high negative values of PC1.

Regarding texture, the explorative PCA conducted on the spectra of 109 olives reveals that $\mathrm{PCl}$ is largely accountable for separating class $c$ corresponding to negative values of PC1 from classes $a$ and $b$, placed, in the PC plan, at positive values of PC1.

According to Yousfi et al. (2006), firmness tends to reduce during

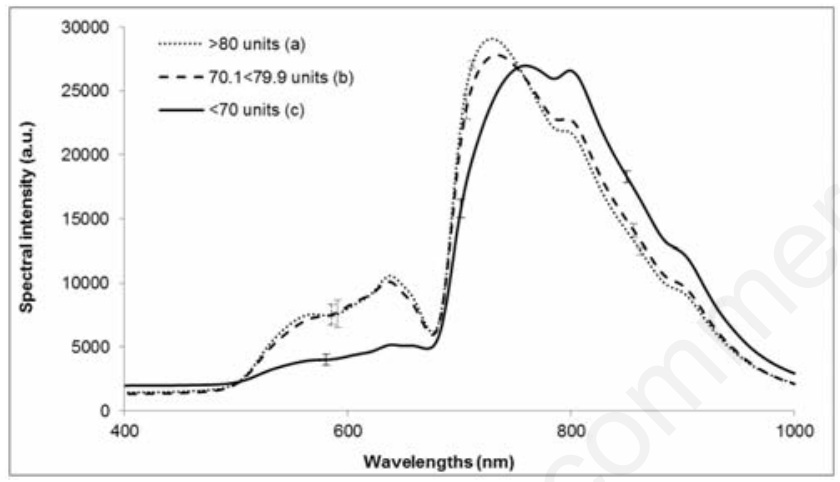

Figure 2. Average raw spectra of 109 olive samples grouped in three classes of texture. Bars indicate the standard error within each group at different wavelengths $(a>80 ; 70.1<b<79.9 ; c<70)$.

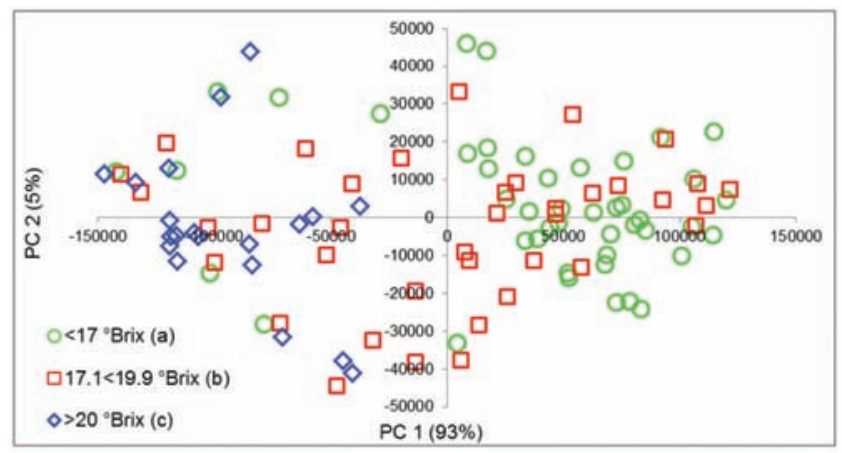

Figure 3. Score plot derived from principal component analysis. The olive samples are divided into three classes according to range of soluble solid content (SSC): $a$ olives with SSC $<17^{\circ} \mathrm{Brix} ; b$ olives with SSC ranging between 17.1 and $19.9^{\circ}$ Brix; $c$ samples with $\mathrm{SSC}>20^{\circ}$ Brix. maturation and the PCA shows the ripening trend in olives from high positive values to high negative values of PC1.

PCs loadings (Figure 5) were analysed in search of main wavelength bands ranges mostly contributing to PC1 and PC2, as candidate discriminators for the class identification. For both studied parameters, the three classes are better detected on PC1. Two main waveband ranges were identified: i) $550-650 \mathrm{~nm}$, in the visible range, where relatively high positive values for $\mathrm{PCl}$ and the maximum positive values of PC2 were found together; ii) $700-750 \mathrm{~nm}$, in the near infrared range, where the two extrema values for both PC1 (maximum) and PC2 (minimum) were found.

\section{Quantitative analysis}

Concerning quantitative analysis, PLS regression models were created for each parameter (Figure 6).

Table 2 shows the results for the PLS regression models for the prediction of SSC and texture.

The results are encouraging. In this preliminary study, the data set available was not particularly wide, so results could be improved with more samples for the elaboration. For example, to verify the robustness of models, an external validation set is required. Regarding SSC, the performance of the regression model can be improved although there

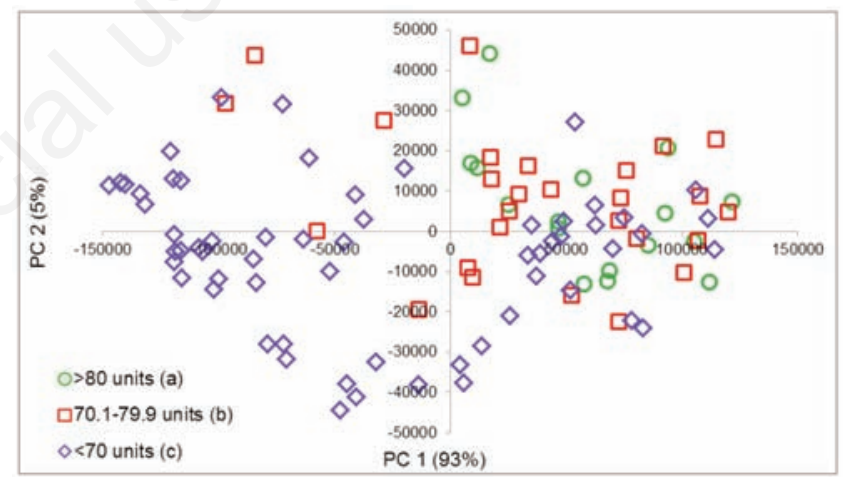

Figure 4. Score plot derived from principal component analysis. The olive samples are divided into three classes according to range of texture: $a$ olives with texture $<70$ units; $b$ olives with texture ranged between 70.1 and 79.9 units; $c$ samples with texture $>80$ units.

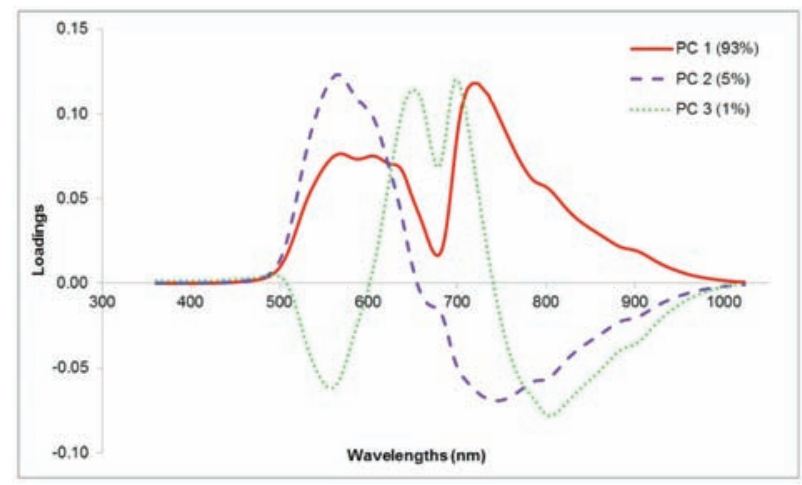

Figure 5. Loading plot derived from principal component analysis. 

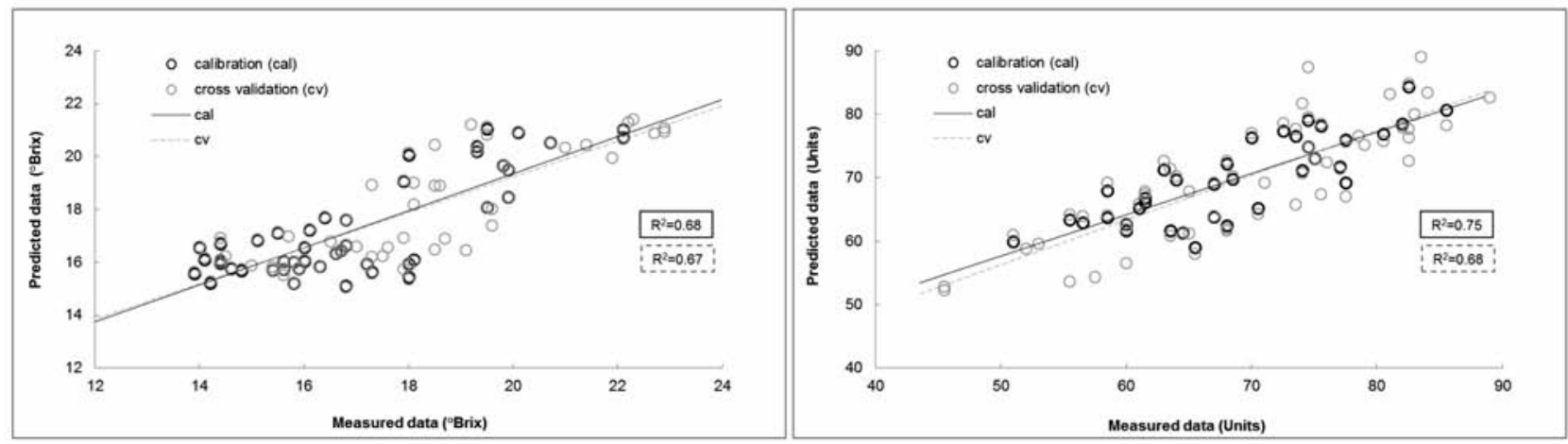

Figure 6. Loading plot derived from principal component analysis.

Table 2. Results of partial last square models for the prediction of soluble solid content and texture.

\begin{tabular}{|c|c|c|c|c|c|c|c|c|}
\hline \multirow[b]{2}{*}{ Parameters } & \multirow[b]{2}{*}{ Data pre-treatment } & \multirow[b]{2}{*}{ No. samples } & \multicolumn{2}{|c|}{ Calibration } & \multicolumn{3}{|c|}{ Cross-validation } & \multirow[b]{2}{*}{ RMSECV\% } \\
\hline & & & $\mathbf{R}^{2}$ & RMSEC & LV & $\mathbf{R}^{2}$ & RMSECV & \\
\hline SSC ( ${ }^{\circ}$ Brix $)$ & Smoothing $+\mathrm{MSC}+$ der $^{2}$ & 80 & 0.68 & 1.36 & 2 & 0.67 & 1.40 & 7.5 \\
\hline Texture (units) & Smoothing + MSC + der $^{2}$ & 88 & 0.75 & 4.92 & 8 & 0.68 & 5.62 & 8.2 \\
\hline
\end{tabular}

$\mathrm{R}^{2}$, coefficient of determination; RMSEC, standard error of calibration; LV, latent variables; RMSECV, standard error of cross validation; SSC, soluble solid content, MSC, multiplicative scatter correction; der², second derivative of the spectrum.

is no particular difference in model evaluation parameters from results reported in literature for the estimation of this parameter on other fruits (Nicolaï et al., 2007) such as apricot (Camps and Christen, 2009) and watermelon (Tian et al., 2007).

Interesting results were obtained in particular for the prediction of berry texture. The possibility of using the reference data on a single berry has allowed good results to be obtained for the estimation of a parameter that is usually difficult to predict, such as the texture of a fruit in an optical non-destructive way. Similar results were obtained for firmness prediction on intact olives by Kavdir et al. (2009) using FTNIR spectroscopy in the wavelength range $780-2500 \mathrm{~nm}$ in reflectance.

A similar study was performed by Salguero-Chaparro et al. (2013) to evaluate different quality parameters. The authors analysed moisture and fat content in intact olive fruits directly on-line using an NIR diode array instrument operating on a conveyor belt. For moisture, fat content and acidity they achieved ratio performance deviation (RPD) values of 2.76, 2.37 and 1.60, respectively. Bellincontro et al. (2012) studied the application of a portable NIR-AOTF tool for on-field prediction of phenolic compounds of olives; prediction models developed for the main phenolic compounds and for total phenols showed very good results with high RPD values for all the indices.

The application of vis/NIR and NIR spectroscopy for the analysis of firmness parameters often encounters considerable difficulties and this was highlighted by some published studies (Nicolaï et al., 2008; Zude et al., 2006). These difficulties are usually due to several factors including the extreme variability of this parameter among berries, the high instrumental error of the penetrometer and, also, the difficulty of calibrating a model for the estimation of an index not directly associable with a chemical species (and consequently the absorption bands of those chemical bonds). The employment of more accurate instrumentation, such as a laboratory texture analyser, for the reference data could improve the prediction capabilities of the models for monitoring and classifying olives.

For these reasons, the predictive capabilities of the model for this parameter are usually poor. In this case, however, results are positive, with $\mathrm{R}^{2}$ about 0.7 in validation and RMSECV\% less than $10 \%$ (RMSECV=5.62 units).

\section{Conclusions}

This work studied the applicability of vis/NIR spectroscopy as a rapid technique to characterise olives directly at the mill just before starting the oil extraction process. In particular, a portable vis/NIR device was tested to estimate two indices: SSC and texture of olive berries.

The prediction capabilities of the system for both parameters were evaluated through the elaboration of prediction models based on multivariate regression techniques. Preliminary results were encouraging, especially regarding estimation of texture. Further studies are needed to confirm these early results to increase the number of samples of the data set available and, consequently, the robustness of prediction models. The use of more accurate instrumentation for the reference data, and the investigation of wavelengths in order to highlight and select the most informative bands, could improve the prediction capabilities of the models to monitor and classify olives directly at the processing mill. Moreover, this technique could also be applied to table olives before the fermentation process. The goal for the future is to provide the sector with post-harvest methods and sorting systems that can provide a quick evaluation of olive fruit ripeness indices and improve management of the oil-making process.

\section{References}

Barreiro P., Ruiz-Altisent M., Moya A., Agulheiro A.C., Garcia-Ramos F.J. 2004. Segregation of soft olives using Durofel and on-line rebound. Spanish J. Agr. Res. 2:493-9.

Beghi R., Spinardi A., Bodria L., Mignani I., Guidetti R. 2013. Apples nutraceutic properties evaluation through a visible and nearinfrared portable system. Food Bioproc. Technol. 6:2547-54.

Bellincontro A., Taticchi A., Servili M., Esposto S, Farinelli D, Mencarelli F. 2012. Feasible application of a portable NIR-AOTF tool for on-field prediction of phenolic compounds during the ripening of olives for oil production. J. Agric. Food Chem. 60:2665-73.

Beltra G., Del Rio C., Sanchez S., Martinez L. 2004. Seasonal changes 
in olive fruit characteristics and oil accumulation during ripening process. J. Sci. Food Agr. 84:1783-90.

Bendini A., Cerretani L., Di Virgilio F., belloni P., Bonoli-Carbognin M., Lercker G. 2007. Preliminary evaluation of the application of the FTIR spectroscopy to control the geographic origin and quality of virgin olive oils. J. Food Qual. 30:424-37.

Bodria L., Fiala M., Guidetti R., Oberti R. 2004. Optical techniques to estimate the ripeness of red-pigmented fruits. Trans. ASABE 47:815-20.

Borzillo A., Iannotta N., Uccella N. 2000. Ointoria tables olives: quality evaluation during ripening and processing by biomolecular components. Eur. Food Res. Technol. 212:113-21.

Camps C., Christen D. 2009. Non-destructive assessment of apricot fruit quality by portable visible-near infrared spectroscopy. Food Sci. Technol. 42:1125-31.

Cen H., He Y. 2007. Theory and application of near infrared reflectance spectroscopy in determination of food quality. Trends Food Sci. Technol. 18:72-83.

Cherubini C., Migliorini M., Mugelli M., Viti P., Berti A., Cini E., Zanoni B. 2009. Towards a technological ripening index for olive oil fruits. J. Sci. Food Agr. 89:671-82.

Conte L.S., Brussolo G., Pizzale L., Carazzolo A., Meurens M., Pavan 0. 2003. Application of near infrared reflectance analysis to olive oil production quality control. Riv. It. Sost. Grasse 80:213-7.

Diaz R., Gil L., Serrano C., Blasco M., Moltó E., Blasco J. 2004. Comparison of three algorithms in the classification of table olives by means of computer vision. J. Food Eng. 61:101-7.

Guidetti R., Beghi R., Giovenzana V. 2012. Chapter 10: Chemometrics in food technology. In: K. Varmuza (ed.) Chemometrics. InTech: EPublishing, New York, NY, USA, pp 217-252.

Kavdir I., Buyukcan M.B., Lu R., Kocabiyik H., Seker M. 2009. Prediction of olive quality using FT-NIR spectroscopy in reflectance and transmittance modes. Biosyst. Eng. 103:304-12.

López-Miranda J., Pérez-Jiménez F., Ros E., De Caterina R., Badimón L., Covas M.I., Escrich E., Ordovás J.M., Soriguer F., Abiá R., de la Lastra C.A., Battino M., Corella D., Chamorro-Quirós J., DelgadoLista J., Giugliano D., Esposito K., Estruch R., Fernandez-Real J.M., Gaforio J.J., La Vecchia C., Lairon D., López-Segura F., Mata P., Menéndez J.A., Muriana F.J., Osada J., Panagiotakos D.B., Paniagua J.A., Pérez-Martinez P., Perona J., Peinado M.A., PinedaPriego M., Poulsen H.E., Quiles J.L., Ramírez-Tortosa M.C., Ruano J., Serra-Majem L., Solá R., Solanas M., Solfrizzi V., de la TorreFornell R., Trichopoulou A., Uceda M., Villalba-Montoro J.M., VillarOrtiz J.R., Visioli F., Yiannakouris N. 2010. Olive oil and health: summary of the II international conference on olive oil and health consensus report, Jaén and Córdoba (Spain) 2008. Nutr. Metab. Cardiovasc. Dis. 20:284-94.

Mailer R.J. 2004. Rapid evaluation of olive oil quality by NIR reflectance spectroscopy. J. Am. Oil Chem. Soc. 81:823-7.
Marquez A.J., Diáz A.M., Reguera M.I.P. 2005. Using optical NIR sensor for on-line virgin olive oils characterization. Sens. Actuat. B Chem. 107:64-8.

Marsilio V., Campestre C., Lanza B., De Angelis M. 2001. Sugar and polyol compositions of some European olive fruit varieties (Olea europaea L.) suitable for table olive purposes. Food Chem. 72:48590.

Massart D.L., Vandeginste B.G.M., Buydens L.M.C., De Jong S., Lewi P.J., Smeyers-Verbeke J. 1997. Handbook of chemometrics and qualimetrics: Part A. Elsevier Science Publ. Co., Amsterdam, The Netherlands, pp 697-8.

Morales-Sillero A., Fernández-Cabanás V.M., Casanova L. 2011. Feasibility of NIR spectroscopy for non-destructive characterization of table olive traits. J. Food Eng. 107:99-106.

Naes T., Isaksson T., Fearn T., Davies T. 2002. A user-friendly guide to multivariate calibration and classification. Vol. 6. NIR Publications, Chichester, UK.

Nicolaï B.M., Beullens K., Bobelyn E., Peirs A, Saeys W, Theron KI, Lammertyn J. 2007. Non-destructive measurement of fruit and vegetable quality by means of NIR spectroscopy: a review. Postharv. Biol. Technol. 46:99-118.

Nicolaï B.M., Verlinden B.E., Desmet M., Saevels S., Theron K., Cubeddu R., Pifferi A., Torricelli A. 2008. Time-resolved and continuous wave NIR reflectance spectroscopy to predict soluble solids content and firmness of pear. Postharv. Biol. Technol. 47:68-74.

Patumi M., d'Andria R., Marsilio V., Fontanazza G., Morelli G., Lanza B. 2002. Olive and olive oil quality after intensive monocone olive growing (Olea europaea L., cv. Kalamata) in different irrigation regimes. Food Chem. 77:27-34.

Salas J.J., Sanchez J., Ramli U.S., Manaf A.M., Williams M., Harwood J.L. 2002. Biochemistry of lipid metabolism in olive and other oil fruit. Prog. Lipid Res. 39:151-80.

Salguero-Chaparro L., Baeten V., Fernández-Pierna J.A., PeñaRodríguez F. 2013. Near infrared spectroscopy (NIRS) for on-line determination of quality parameters in intact olives. Food Chem. 139:1121-6.

Tian H., Ying Y., Lu H., Fu X., Yu H. 2007. Measurement of soluble solids content in watermelon by VIS-NIR diffuse transmittance technique. J. Zhejiang Univ. Sci. 8:105-10.

Yousfi K., Cert R.M., Garcia J.M. 2006. Changes in quality and phenolic compounds of virgin olive oils during objectively described fruit maturation. Eur. Food Res. Technol. 223:117-24.

Zanoni B., Bertuccioli M., Rovellini P., Marotta F., Mattei A. 2005. A preliminary approach to predictive modelling of extra virgin olive oil stability. J. Sci. Food Agric. 85:1492-8.

Zude M., Herold B., Roger J.M., Bellon-Maurel V., Landahl S. 2006. Non-destructive tests on the prediction of apple fruit flesh firmness and soluble solids content on tree and in shelf life. J. Food Eng. 77:254-60. 